\title{
Uncovering K-12 Youth Engineering Design Thinking through Artifact Elic- itation Interviews
}

\section{Dr. Suzanne Eyerman, Fairhaven Research and Evaluation}

Suzanne Eyerman, Ph.D. is a researcher and evaluator for STEM programs in higher education and in K-12 classrooms and afterschool programs. A former classroom teacher, Dr. Eyerman's has investigated learning in a variety of contexts including school playgrounds and children's museums. Currently, her works focuses on increasing the participation of women and people of color in engineering and computer science. Dr. Eyerman received her B.A. in Psychology from Monmouth University and her Ph.D. in Education from the University of Colorado, Boulder. Her research interests are in the areas of girls' and women's identities in STEM fields, engineering and computer science in K-12 education, and iteration.

\section{Dr. Sarah Hug, University of Colorado, Boulder}

Dr. Sarah Hug is Research Associate at the Alliance for Technology, Learning, and Society (ATLAS) Institute, University of Colorado at Boulder. Dr. Hug earned her PhD in Educational Psychology at the University of Colorado, Boulder. Her research and evaluation efforts focus on learning science, technology, engineering, and mathematics, with a special interest in communities of practice, creativity, and experiences of underrepresented groups in these fields across multiple contexts.

Emily McLeod

Dr. Tania Tauer, Techbridge Girls 


\title{
Uncovering K-12 Youth Engineering Design Thinking through Artifact Elicitation Interviews
}

\begin{abstract}
This exploratory research paper investigated the use of artifact elicitation interviews [1] in understanding youth meaning-making following design-based afterschool engineering activities. The Next Generation Science Standards bring engineering design content to K-12 students in formal settings, yet little is known about how to formally assess learning throughout the design process, particularly at the earlier grade bands (i.e., grades 3-5). In an effort to assess design thinking, 102 interviews with girls were videotaped across elementary and middle school programs in two cities. The interviews called on youth to give a guided, narrative description of their work on a design project accomplished in their engineering-focused, girls-only afterschool program. Interviews were augmented with programmatic observations, so the analysts could triangulate evidence from interviews with observations of girls engaged in the projects. In collaboration with the curriculum development team, a rubric was developed to measure the extent to which girls communicated effective engineering design, specifically: a) understanding of the design challenge, b) evaluation of design strengths and weaknesses, and c) evidence that participants were making decisions based on testing. Additionally, the participants were rated on their ability to describe the engineering design process.
\end{abstract}

Themes emerged from the data related to program implementation as well as interview implementation. First, project specificity and the existence of formal testing procedures embedded in the whole group activity supported youth descriptions of testing failures and redesign practices. Second, the physical use of the artifact in communicating knowledge was evident in many interviews in which the youth may have lacked scientific language to describe their reasoning - gesture and referential language (e.g., pointing to an element and stating, "This part") assisted coders in understanding whether youth had conceptual understanding of design features. Finally, understanding of the engineering design process was expressed in multiple ways. Interview responses indicated implicit understanding of the engineering design process through the narrative that youth used to describe product development. In another segment of the interview, youth were asked to describe the engineering design process to measure explicit understanding. The analysts found incongruent responses related to implicit and explicit understanding of the engineering design process.

Introduction

"You figure out what you want to do, you design it, you write it out, you build it, you present, you rebuild. It goes around in circles." Samara (pseudonym), Middle School student

"First you draw out your plans, then you collect your supplies, then you build his body, then you code it on this. You can keep going around again if you have enough time, so you could maybe attach an arm here and make it move like this." Mina (pseudonym), Middle School student 
These excerpts were captured in video-recorded interviews of elementary and middle school students who participated in girls' engineering afterschool programs in Seattle and Washington, DC. Researchers used artifact elicitation interviews to assess girls' understanding of the cyclical nature of the engineering design process. In the first interview excerpt, Samara offered a succinct explanation. She explained the engineering design process as a cycle, saying that it "goes around in circles," which indicated her understanding of the process as ongoing. The other interviewee quoted here, Mina, described the engineering design process within the context of her project as she pointed to various parts of her creation. Mina was seated with her project in front of her, and she gestured to it as she spoke. She conveyed her perspective of the process as cyclical by saying, "You can keep going around again," in reference to the continual nature of the design process. Each girl, in her own way, was able to communicate the engineering design process such that analysts could conclude that the girls understood it as ongoing.

These interviews were part of a larger study of a nonprofit's expansion to provide engineering education to more girls. That nonprofit, Techbridge, seeks particularly to serve girls of color and girls in lower-income neighborhoods with a goal of inspiring girls to discover their passion for science, engineering, and technology (SET). The major goal of Techbridge is to help girls see SET careers as a possibility for their own futures because the girls know they have the ability to succeed in those fields. To accomplish this, Techbridge helps girls learn some technical skills in SET fields, gauge their interest in a variety of areas, and have up-close experiences interacting with SET professionals in their workplaces. In Techbridge's afterschool programs, girls from grades 4 through 12 learn technical skills in science, engineering, and technology while working on projects together, and they also take field trips to local technology companies and meet regularly with role models who are professionals working in technology careers. Girls often return for consecutive school years to participate in the afterschool program, and some elect to take part in intensive summer day camps.

The authors are a pair of researchers and a pair of Techbridge staff members. The researchers' role with Techbridge has been as the education research team for an expansion of the Techbridge afterschool program to multiple other regional sites across the United States. The expansion has also been watched over by a team of evaluators who are also external to Techbridge, and we researchers have collaborated, at times, with the evaluation team on data collection. The role for the researchers has enabled us to explore this idea of engineering design with a good deal of depth, while also having access to a variety of data sources and information across time that a small research team may not have collected independently. The girls who were recorded for this analysis have become somewhat familiar with the researchers over the five years of the larger researcher study, of which this analysis is a part. Though some of the girls were new to the program or had perhaps been absent for previous visits of the researchers, many of the girls had seen at least one of the two researchers at least once prior to being interviewed for these artifact elicitation interviews. Some level of familiarity with the girls, the school staff, the Techbridge staff, and the regular routines of the afterschool program enabled the researchers to understand and contextualize the girls' projects and explanations for this analysis. The Techbridge staff members served as consulting authors for this work, as they have additional up-close knowledge of the organization's curriculum and processes, in addition to having interactions with the girls who participate in the afterschool program. That is, the staff members served here as invaluable 
insiders who could provide member checks for the researchers as they developed the engineering design assessment techniques and tool and then proceeded with data analysis.

Engineering design

The engineering design process is a methodology for approaching engineering problems: a series of steps that engineers use cyclically to solve problems by creating products or processes. The Accreditation Board for Engineering and Technology (ABET), the organization that accredits colleges and universities in applied and natural sciences in the U.S., defines the engineering design process as a recurring decision-making process that converts resources to meet a specified need [2]. That is, engineering design is the process by which science and mathematics become engineered solutions.

The steps within the process are characterized differently by different groups, though similar aspects are seen across groups. The girls' engineering afterschool program from this research study characterizes the process this way: identify, brainstorm, choose, design, test, show, redesign (see Figure 1). NASA, for example, names the steps in the process slightly differently: ask, imagine, plan, create, experiment, improve [3].

Figure 1. Techbridge's Engineering Design Process

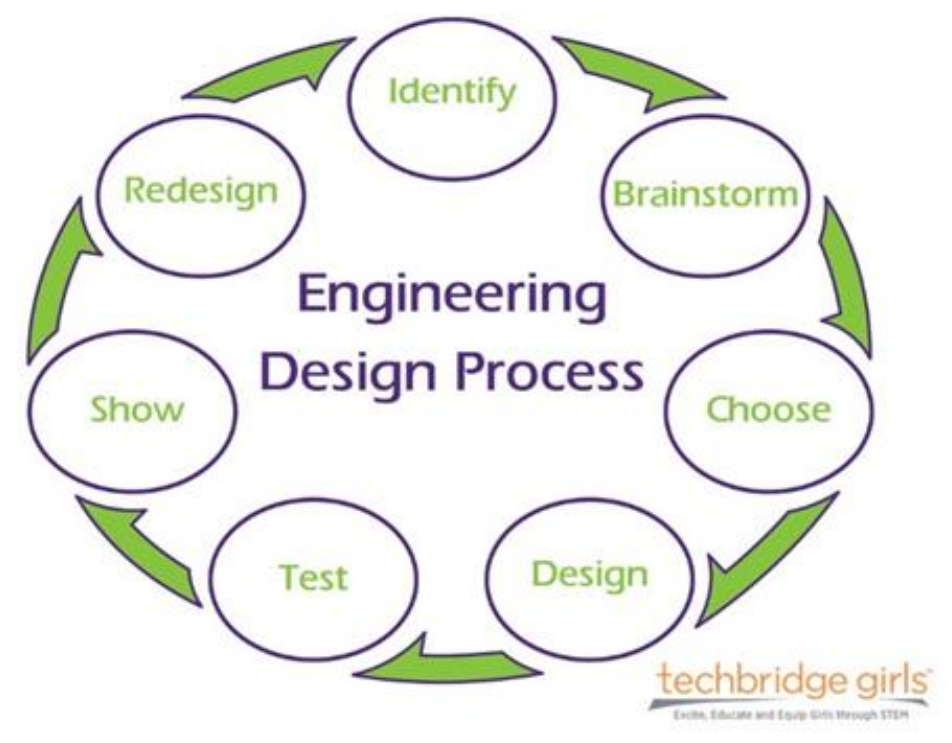

Of great importance to the engineering design process is the idea that it is cyclical. As in Figure 1 , engineering design is often pictured as words that are placed as if on the edge of a circular shape and connected by arrows that show the words flowing from one to the next. Another word often used by engineers is "iterative", meaning that the process is repeated as engineers refine their solutions to meet the defined need. Within engineering education, we have seen educators emphasize that there are no failures in engineering, just opportunities for redesign. Engaging in the engineering design process within education is intended as a way for youth to practice encountering challenges and persevering through them to create a solution [4]. 
Helping students learn about, and learn how to use, the engineering design process is a major aim of engineering education [5]. Engineering design is useful in practice because it allows students to make mental models concrete and offers time to make decisions, reflect, communicate, and collaborate [6]. Additionally, understanding engineering design is important because the process is used by engineers in all professional fields [7]. Because of its prevalence among professionals, the process is key to engineering education, as evidenced by the emphasis within NGSS standards for K-12 education and ABET's accreditation criteria for post-secondary education.

Methodology: Artifact elicitation as a method for uncovering engineering design thinking

For this investigation, 102 interviews with girls were videotaped being interviewed about their engineering projects. This occurred across elementary and middle school programs in two cities. Girls in grades four through eight participated. All participants lived in low-income neighborhoods in the Greater Seattle Area or in Washington, DC. Interviews were supplemented with observations of the afterschool program, so the analysts could better understand the context of the projects and interviews by observing girls engaged in their engineering projects.

Researchers were also able to triangulate observations and interviews with member checks by speaking with program facilitators (i.e., Techbridge staff) who served as consulting authors on this paper.

In seeking to assess Techbridge's participants' understanding of engineering design, the researchers sought an assessment that offered girls an opportunity to explain and demonstrate their understandings fully while also keeping the assessment process brief enough that many participants could be assessed. Researchers did not pursue evaluations of completed projects or more formal, written evaluations. Researchers instead chose an assessment method of interviews that consisted of girls being asked questions about the engineering design process as it related to their current project. The Techbridge program is project-based in that girls learn concepts of engineering design within the context of a series of single- or multi-session projects during their participation in the afterschool program. Asking Techbridge girls to describe engineering design in a more abstract setting, such as one not anchored in one of their engineering projects, had led to interviews in the past that were so abstract as to be confusing to researchers. The researchers instead chose an approach in which girls had their current, or recently completed, engineering projects on the table with them while being interviewed. Having the physical project present as an artifact to which they could refer grounded the interview in specifics: girls pointed to particular parts of their project as they spoke and based their answers on actions they had taken to create their projects. Artifact elicitation can help evoke memories, stimulate new insights, and provoke greater understanding in interviews [1].

To be able to review the girls' interview videos in a more subjective, standardized way, researchers created two rubrics. We thought about the areas of learning that we wanted to assess, and then we searched for existing ideas or standards to include in our rubric. Researchers split the task of assessing girls' thinking around engineering design into two parts: how effectively girls understood parts of the design process and how effectively they communicated their understanding of the design process as cyclical. 
Researchers also created a series of five questions, plus follow-up and sub-questions for use if girls seemed confused or were unable to answer each of the main questions, to structure the interviews around the ideas that were being assessed. Interviews of girls typically lasted four to five minutes, though some were as short as two minutes and some were as long as 10 . To establish inter-rater reliability, two analysts viewed all videos at least twice during rubric development, and the analysts discussed the video and formed consensus on a numeric value when rubric scores differed. After the rubrics had been iteratively tested and revised such that the two analysts reliably applied the same scores to videos, the rubrics were deployed for use in data analysis. During the data analysis phase, analysts sometimes assigned scores by watching videos together, separately assigning scores, and then discussing any divergences. At other times, analysts worked individually to watch videos and assign scores. Overall, at least one-third of all videos were scored by at least two analysts.

For this analysis, researchers first looked to the engineering standards based on the Next Generation Science Standards to assess how well the participants understood parts of the design process. This part of the rubric refers mainly to evidence of girls' knowledge of the design criteria and constraints, plus using reasoned decision making from data to design and build solutions.

Next Generation Science Standards (NGSS) for engineer education in Kindergarten through high school have been created by a partnership among the National Science Teachers Association, the National Research Council, and American Association for the Advancement of Science, and Achieve [8]. These NGSS narrow the engineering design process into three parts: defining the problem, developing possible solutions, and improving designs. Although the standards were designed for classroom settings, the researchers made use of them with this afterschool program because of the program's aim to have a robust engineering curriculum. Given their purpose, the researcher team found it appropriate to use NGSS as a starting point for assessing whether girls gained an effective understanding of engineering. It should be noted that although NGSS includes rubrics for scoring engineering lessons in K12 education settings, the rubrics are designed to score instruction and not to gauge students' understanding, which is why the researchers had to create a new rubric for this analysis.

The NGSS for engineering consist of four learning goals, which researchers placed into a table format, assigned a numeric score as the goals progress toward greater challenge, and then provided information about each score. To refine and further define the rubric, a team of three analysts watched pilot videos of girls talking about their engineering projects. Researchers were then able to include sample justifications for analysts to reference when assigning scores to videos (see Table 1). The NGSS standards-related rubric was developed to be used to assess the video interviews holistically, not to relate directly to a specific interview question. 
Table 1

Rubric for scoring in relation to the NGSS standards

\begin{tabular}{|c|c|c|}
\hline Score & Criteria Description & Sample Justification \\
\hline 0 point & $\begin{array}{l}\text { Techbridge girls do not indicate } \\
\text { understanding of the problem/challenge } \\
\text { and constraints }\end{array}$ & \\
\hline 1 point & $\begin{array}{l}\text { Techbridge girls will be able to address } \\
\text { the criteria and constraints of a design } \\
\text { problem. Focus is on understanding the } \\
\text { task and recognizing how different } \\
\text { factors could influence task success } \\
\text { (Relates to NGSS standard MS-ETS1-1) }\end{array}$ & $\begin{array}{l}\text { A Techbridge participant describes her } \\
\text { task as "creating a toy that moves with } \\
\text { a motor." }\end{array}$ \\
\hline 2 points & $\begin{array}{l}\text { Techbridge girls will be able to evaluate } \\
\text { competing design solutions using a } \\
\text { systematic process. Focus is on } \\
\text { engaging in argument and decision- } \\
\text { making about designs. (Relates to NGSS } \\
\text { standard MS-ETS1-2) }\end{array}$ & $\begin{array}{l}\text { A Techbridge participant said her } \\
\text { group started with the idea of building } \\
\text { a carousel to move the water, "but that } \\
\text { didn't work." They decided to try a fan } \\
\text { and a pump. The participant's response } \\
\text { acknowledges that multiple designs } \\
\text { could solve the problem but did not } \\
\text { reason about product failures. }\end{array}$ \\
\hline 3 points & $\begin{array}{l}\text { Techbridge girls will be able to analyze } \\
\text { data from tests to determine similarities } \\
\text { and differences among design solutions. } \\
\text { Focus is on data-based decisions and } \\
\text { some beginning reasoning about why } \\
\text { designs "worked" or "didn't work." } \\
\text { (Relates to NGSS standard MS-ETS1-3) }\end{array}$ & $\begin{array}{l}\text { A participant described her project } \\
\text { work: the first design they developed } \\
\text { had pipes that were not tall enough to } \\
\text { reach the bucket above. They modified } \\
\text { the design so that the pipes reached the } \\
\text { bucket, and this redesign was slightly } \\
\text { more effective. }\end{array}$ \\
\hline 4 points & $\begin{array}{l}\text { Techbridge girls will be able to develop } \\
\text { a model to generate data for iterative } \\
\text { testing and modifications. Focus is on } \\
\text { development of next iteration, or } \\
\text { definitive plan for reiteration that } \\
\text { addresses the previous design's } \\
\text { shortcomings. (Relates to NGSS } \\
\text { standard MS-ETS1-4) }\end{array}$ & $\begin{array}{l}\text { A Techbridge participant described } \\
\text { advice she would give another girl who } \\
\text { was doing her project. She explained a } \\
\text { technique: soldering. While she did not } \\
\text { have time to accomplish this for her } \\
\text { own project, she thought it would } \\
\text { improve her project design because it } \\
\text { would "get the wires out of the way". }\end{array}$ \\
\hline
\end{tabular}

The other rubric created for this analysis assesses video interviews for evidence of girls' understanding of the engineering design process as cyclical. The same holistic rating approach was true as well for this rubric: each video interview was assessed overall in terms of a girl's ideas about engineering design as ongoing and was not dependent on how she answered a specific question. This aspect of rating videos indicates the way that video evidence, rather than audio recordings or written transcripts, is essential for embedded assessment; vocal tone and 
facial expression were additional factors in making meaning of girls' utterances. Table 2 contains the rubric used for assessing girls' views of engineering design as cyclical, that is, how she viewed project setbacks and perseverance toward a design solution.

Table 2

Rubric for scoring whether participants viewed the design process as cyclical

\begin{tabular}{lll}
\hline Score & Criteria Description & Sample Justification \\
\hline 0 point & $\begin{array}{l}\text { Techbridge girl indicates no redesign or } \\
\text { indicates giving up immediately when } \\
\text { faced with a challenge }\end{array}$ & $\begin{array}{l}\text { A Techbridge girl said, "We tried to } \\
\text { build a tower, but it didn't work. It fell } \\
\text { over." }\end{array}$ \\
& $\begin{array}{l}\text { Techbridge girl gives a response that is } \\
\text { mixed, one that may have some } \\
\text { indication of understanding design as } \\
\text { cyclical but with some additional } \\
\text { negative or inconclusive evidence }\end{array}$ & $\begin{array}{l}\text { A participant describes her group as } \\
\text { "trying to give up, but in the end we } \\
\text { kept working on the design," or saying, } \\
\text { "It didn't work, but we'd tried our } \\
\text { best." }\end{array}$ \\
$\begin{array}{l}\text { Throughout the interview, the girl } \\
\text { describes the project as an ongoing } \\
\text { process. She refers to making continual } \\
\text { progress, rather than the dichotomous } \\
\text { ideas of working versus not working. } \\
\text { She views the process as cyclical, not } \\
\text { failure/terminal. }\end{array}$ & $\begin{array}{l}\text { A Techbridge girl describes how } \\
\text { changes made to the project enhanced } \\
\text { the way it performed the task. She had } \\
\text { ideas for redesign even following } \\
\text { technical challenges, showing } \\
\text { continued interest in the improvement } \\
\text { of the project. }\end{array}$
\end{tabular}

The rubrics that were created are broad and not intended to be a considered as a way to "grade" an individual's performance, or the performance of a teacher or facilitator, on a project. Rubric scores of a girl's interview should be considered over time, over multiple interviews, and more as a way to consider growth in skills and potentially the development of new ways of thinking. One possible use for the rubric would be to use it to assess near the beginning and the end of the year with several girls at each Techbridge site to compare individuals' growth over time. Another way to use the rubric would be at a few points over the year with a subset of girls to compare different curricula and the way implementation of various projects or units can provoke thinking (or not) about engineering.

Artifact elicitation interviews in practice at a girls' engineering afterschool program

NGSS standards

The rubric for the NGSS Standards includes understanding the design challenge, evaluating completing design solutions, analyzing data, and developing a model for testing. Scores have ranged from 0 , showing no indication of understanding of challenge and constraints, to 4 , having developed a model for testing (see Table 1). Scores of 4 have been rare, some videos have received scores of 0 , and scores of 1,2, and 3 have been most common over time (see Table 2). The median score was 2 . 
Table 2

NGSS Standards Scores, $n=102$

\begin{tabular}{cc}
\hline Score & Count \\
\hline 0 & 8 \\
1 & 18 \\
2 & 43 \\
3 & 32 \\
4 & 1 \\
\hline
\end{tabular}

Engineering design process as ongoing

The second part of the rubric for engineering design process assessed girls' understanding of engineering design as an ongoing or cyclical process. That is, this rubric helped researchers gauge the way Techbridge participants talked about the iterative nature of the process. Possible scores are 0 (no substantial evidence of understanding of redesign), 1 (mixed or inconclusive evidence), or 2 (girl viewed engineering as an ongoing process). Only 3 videos have ever received scores of 0 , and most have received scores of 1 or 2 (see Table 3 ). The median score was 2.

Table 3

Design Process as Cyclical, $n=102$

\begin{tabular}{cc}
\hline Score & Count \\
\hline 0 & 3 \\
1 & 42 \\
2 & 57 \\
\hline
\end{tabular}

Implications for lesson design

Researchers found that certain lessons afforded higher scores. That is, not all engineering projects were equally suited for assessing engineering design thinking through artifact elicitation interviews. While viewing and scoring videos, analysts noticed that some project lessons contained an explicit testing component, which seemed to coincide with higher scores on the NGSS rubric. One such project was for girls to make a water filtering device, and they were given dirty water to filter during their designing process. In contrast, a project without testing component asked girls to build a gingerbread house. In the case of the water filter, the girls could actually test their product as they worked on it. The gingerbread house, in contrast, did not have a testing component. This was, at least in part, because it did not solve a specific problem. Was it possible that some projects seemed to lend themselves to greater understanding of engineering design because the projects required testing during the design process? Researchers pursued this question by conducting an independent-samples t-test to compare means of explicit testing projects and non-explicit testing projects. There was a significant difference for the scores for explicit testing $(\mathrm{M}=2.6, \mathrm{SD}=0.71)$ and non-explicit testing $(\mathrm{M}=1.88, \mathrm{SD}=0.83) ; t(48)=3.30, p=$ 0.0019. These results suggest that explicit testing really does have an effect on NGSS scores. Specifically, results suggest that participants conveyed greater understanding of the engineering design process when interviewed about projects that had explicit testing components. It is 
hypothesized that project work that includes testing creates a better foundation for understanding the engineering design process.

Lesson implementation was also found to be consequential. Although scores were not designed to assess the performance of lesson facilitators (i.e., teachers or Techbridge staff), analysts did assign low NGSS rubric scores to video interviews that related to projects in which lesson facilitators did not introduce the problem to girls in a structured manner. Researchers were able to draw this conclusion because they had also been present to observe lesson implementation. Researchers hypothesize that the lesson facilitators who gave unstructured introductions to projects contributed to girls' vague understandings of a project's challenges and constraints. That is, interviews that received scores of 0 were for cases in which girls were not able to communicate their understanding of the challenge and constraints because the projects had not been presented to them with enough specificity.

Implications for assessment

The benefit of having an artifact present to assist in communicating understanding was evident in many interviews. Youth sometimes lacked scientific language or were not adept at communicating engineering problem solving. The physical object (e.g., figures from Claymation video, partially-built foam robot, toothpick and gumdrop dome), however, was present and enabled many of the girls to describe their reasoning via gesture and referential language. They could, for example, point to part of their robot and say, "This part," which assisted analysts in understanding whether youth had conceptual understanding of design features. The presence of the object also seemed to stimulate memories of how they had created it, plus spark new insights.

Participants spoke about the engineering design process in a variety of ways with varying degrees of clarity. In some responses, girls were able to list and then intricately describe the steps of the engineering design process. Girls sometimes only listed off the steps of engineering design. Others did not have words to describe the process (i.e., did not say "redesign") but were able to adequately relay their understanding because of how they described what they did within the context of their specific engineering project. The rubrics were designed to be inclusive and holistic tools: girls' communicated understandings could be assigned appropriate scores regardless of the particular words that were used or the order in which the process was relayed.

Conclusions

This research project has sought to look closely at girls' understanding of engineering design in an afterschool program. Assessments of learning are often overlooked in the world of informal education, though here researchers and program staff worked together to create a methodology for this important work. Artifact elicitation interviews allowed girls to reference their engineering projects and explain their process. Without having such a window into girls' understanding of engineering design, program staff would not have a standardized way of gauging girls' learning.

Researchers were able to draw several conclusions from this analysis. First, the inclusion of formal testing and greater specificity during a project's introduction increased participants' 
understanding of engineering design. Second, the use of physical artifacts to communicate knowledge and understanding interviews was useful for instances in which youth may have lacked scientific language to describe their reasoning because it enabled girls' use of gesture and referential language to communicate conceptual understandings. Finally, the holistic application of rubrics to interview data allowed for understandings of the engineering design process to be expressed in multiple ways: both implicit and explicit understandings could be expressed by participants and then scored by analysts' application of the rubrics to each participant's interview as a whole.

\section{References}

[1] E. P. Douglas, S. S. Jordan, M. Lande, and A. E. Bumbaco, "Artifact elicitation as a method of qualitative inquiry in engineering education," in ASEE Annual Conference \& Exposition, Seattle, WA, USA, June 2015.

[2] Engineering Accreditation Commission. "Criteria for accrediting engineering programs," Accreditation Board for Engineering and Technology, Baltimore, MD, 2014.

[3] National Aeronautics and Space Administration, Engineering design process. Available: https://www.nasa.gov/audience/foreducators/best/edp.html, 2017.

[4] P. S. Lottero-Perdue, "The engineering design process as a safe place to try again: Responses to failure by elementary teachers and students," in Annual Meeting of NARST, Chicago, IL, USA, April 1015.

[5] National Research Council. "A framework for K-12 Science education: Practices, crosscutting concepts, and core ideas,” The National Academies Press, Washington, DC. Available: https://doi.org/10.17226/13165, 2012.

[6] K. B. Wendell and J. L. Kolodner, "Learning disciplinary ideas and practices through engineering design," in Cambridge Handbook of Engineering Education Research, A. Johri and B. M. Olds, Eds. New York, NY: Cambridge University Press, 2014, pp. 243265.

[7] G. Pahl and W. Beitz, Engineering design: a systematic approach. London, UK: Springer Science \& Business Media, 2013.

[8] Next Generation Science Standards, "NGSS development overview." Available: https://nextgenscience.org/development-overview, 2013. 